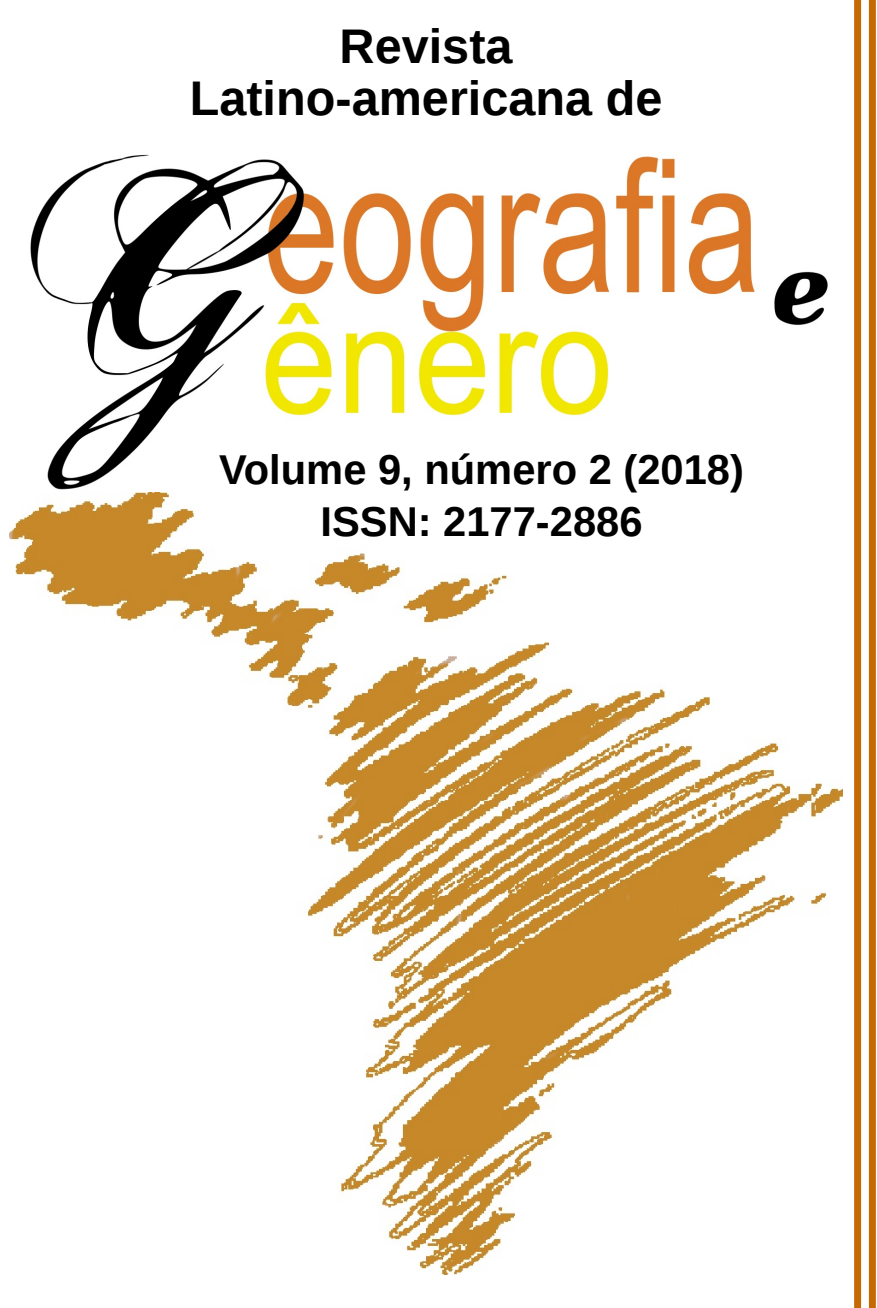

\title{
¿Y Cómo y Dónde lo Hacemos? Experiencias Reproductivas de Mujeres Lesbianas
}

'Como e Onde Fazemos Isso?' Experiências Reprodutivas de Mulheres Lésbicas

'And How and Where do we do it?' Reproductive Experiences of Lesbian Women

\author{
Mercè Falguera Ríos \\ Investigadora Independiente - Espanha \\ mercefalguera@gmail.com
}

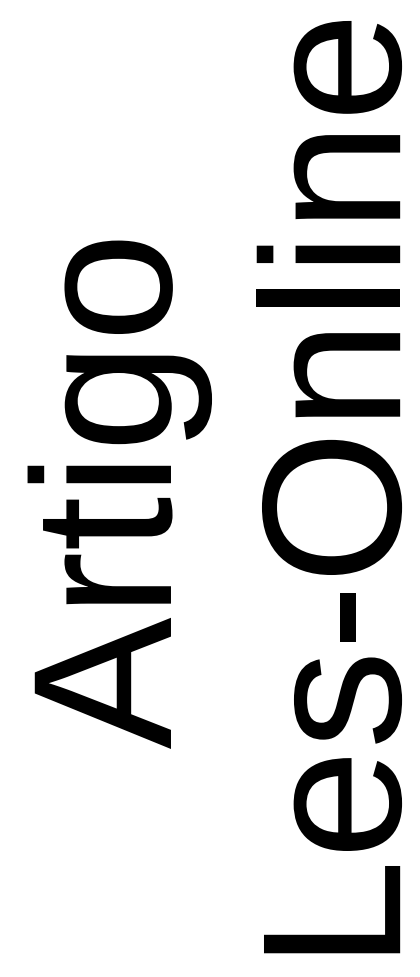

Como citar este artigo:

FALGUERA RÍOS, Mercè. ¿Y Cómo y Dónde lo Hacemos? Experiencias Reproductivas de Mujeres Lesbianas. Revista Latino Americana de Geografia e Gênero, v. 9, n. 2, p. 237-251, 2018. ISSN 21772886.

Disponível em:

http://www.revistas2.uepg.br/index.php/rlagg 


\title{
¿Y Cómo y Dónde lo Hacemos? Experiencias Reproductivas de Mujeres Lesbianas
}

\section{‘Como e Onde Fazemos Isso?’ Experiências Reprodutivas de Mulheres Lésbicas}

\section{'And How and Where do we do it?' Reproductive Experiences of Lesbian Women}

\section{Resumen}

En el momento que las mujeres lesbianas, ya sea en solitario o en pareja, se plantean tener criaturas se abre todo un abanico de posibilidades de cómo hacerlo (diversas técnicas reproductivas, procesos de adopción, etc.). A partir del trabajo doctoral de la autora, realizado en Catalunya (España), se muestra como las mujeres lesbianas participantes han accedido a sus proyectos maternales. El artículo muestra cómo las informantes han sentido "la llamada de la maternidad", cómo y cuándo deciden ser madres y si se plantean repetir la experiencia maternal. Estas cuestiones se abordan a partir de las experiencias y las voces de las protagonistas de esta investigación. A partir de las entrevistas y los materiales etnográficos, se pretende mostrar cómo las informantes construyen sus comaternidades lésbicas.

Palabras-Clave: Lesbiana; Técnicas Reproductivas; Maternidad; Lesboparentalidad.

\section{Resumo}

No momento que as mulheres lésbicas, sejam solitárias ou com companheira, planejam ter uma criança, se abre todo um leque de possibilidades de como fazer-lo (diversas técnicas reprodutivas, processos de adoção, etc.). a partir do trabalho doutoral da autora, realizado na Catalunia (Espanha), se evidencia como asmulheres lésbicas participantes tem acessado seus projetos maternais. O artigo mostra como as informações tem sentido "a chamada da maternidade" como e quando decidem ser mães e se planejam repetir a experiência maternal. Estas questões são abordadas a partirdas experiênciias e das vozes das protagonistas dainvestigação. A partir das entrebvistas e dos materiais etnográfgficos, evidenciamos como as informantes constrõem suas co-maternidades lésbicas.

Palavras-Chave: Lésbicas; Técnicas Reprodutivas; Maternidade; Lesboparentalidade.

\begin{abstract}
When lesbian women, alone or in a couple, consider having children, there is a whole range of possibilities available (various reproductive techniques, adoption processes, etc.). From the author's doctoral work, held in Catalonia (Spain), it is shown how participating lesbian women accomplished their maternal projects. The article shows how informants felt "the call of motherhood", how and when they decide to become mothers, and if they want to repeat their motherhood experience. These issues are addressed based on the experiences and voices of the participants in this research. Based on interviews and ethnographic materials, it is intended to show how informants build their comaternal lesbian projects.
\end{abstract}

Keywords: Lesbian; Reproductive Techniques; Maternity; Lesbian Maternity. 
Este artículo parte del trabajo doctoral de la autora en relación a las comaternidades lésbicas, realizado en Catalunya, dentro del programa de doctorado en antropología de la Universitat de Barcelona. La tesis ${ }^{1}$ se centró en las experiencias maternales de un grupo de mujeres que tuvieron filiación con otras mujeres, o en solitario, a partir de técnicas de reproducción asistida (TRA).

El objetivo general de la tesis era analizar la construcción cultural y las prácticas de las familias formadas por mujeres lesbianas desde las vivencias de las propias mujeres. La pregunta principal a la que la investigación quería dar respuesta era cómo construían las mujeres lesbianas sus maternidades, cómo las pensaban, cómo las sentían y cómo las vivían. Esta pregunta venía acompañada de otras secundarias: cómo y cuándo se planteaban ser madres, qué técnicas de reproducción asistida utilizaban, cómo vivían ese proceso, cómo elegían al donante, qué papel jugaba la madre social, cómo se producía la salida del armario como familia y cómo gestionaban sus maternidades en una sociedad heteropatriarcal. La hipótesis principal era que las mujeres lesbianas que utilizaron TRA construían sus maternidades más allá del vínculo biológico.

En esta investigación se abordó la complejidad de las maternidades desde una posición feminista que contempla con otra mirada las relaciones maternofiliales y, al mismo tiempo, rechaza la "institución materna" (Rich, 1996). Al reentender la maternidad en un sentido amplio, intenta desligarla de las representaciones hegemónicas que aseguran la permanencia de las mujeres bajo el control masculino y plantea la distinción entre la maternidad como institución y como experiencia (RICH, 1996). En el contexto social actual, una sociedad claramente heteropatriarcal, continúa presente en el imaginario colectivo una identificación esencialista de la feminidad con la maternidad, de manera que las mujeres quedan definidas por su función reproductiva (TUBERT, 1996, 1991; SALETTI CUESTA, 2008). La maternidad, en tanto que institución, ha construido todo un orden simbólico que produce una idealización y ha creado, al mismo tiempo, un patrón de conducta a través de la figura de la madre. En el caso de las madres lesbianas sus dos identidades pueden ser vistas como contradictorias. En la madre lesbiana confluye una identidad marginada (situada al margen), que es la de lesbiana, con una de las más reverenciadas, la de madre (HEQUEMBOURG; FARRELL, 1999). Además, socialmente se ha considerado a las mujeres cisgénero lesbianas como mujeres estériles e incapaces de ejercer la maternidad, por su preferencia sexual y sus relaciones sexoafectivas. En este sentido, Ellen Lewin nos dice:

reclamar el derecho a ser madre supone el repudio de las convenciones de género que definen 'madre' y 'lesbiana' como identidades inherentemente incompatibles, la primera natural e intrínseca a la mujer, organizada en torno al altruismo, la segunda antinatural y organizada entorno al egocentrismo. (LEWIN, 1994, p. $350)$.

1 La tesis fue defendida en diciembre de 2016. Se puede consultar en la web de Tesis Doctorales en Xarxa, en: http://hdl.handle.net/10803/525828. 
Asimismo, como señala esta misma autora "vivir como una madre significa crear otras opciones, y estas opciones rescriben la oposición entre 'madre' y 'lesbiana'" (LEWIN, 1994, p. 350). En nuestro contexto, Silvia Donoso (2002) destaca que "lo que la ideología de parentesco gay-lésbico rechaza es la naturalización de los lazos familiares poniendo en ecuación la conexión biológica con el parentesco per se" (2002, p. 172). En este mismo sentido, Claudia Fonseca señala cómo estas formas de familia "sacuden los cimientos de las creencias acerca de lo que es 'natural': la 'familia nuclear tradicional', la procreación sexuada y la filiación biogenética” (2007, p. 1).

El trabajo de campo se realizó en la provincia de Barcelona entre el mes de diciembre de 2011 y mayo de 2013. La técnica utilizada en el trabajo de campo fue la historia de vida, como herramienta que profundiza en las trayectorias vitales de cada una de las mujeres. El número de familias entrevistadas fue 16, de las cuales 14 eran biparentales (una de ellas era familia reconstituida), una era madre soltera por elección y otra madre divorciada. Nueve de ellas residían en ciudades de más de 20.000 habitantes y siete de ellas en pueblos o ciudades de menos de 20.000 habitantes. La mitad del grupo de familias era de una asociación de familias homoparentales y la otra mitad no, con la idea de diferenciar experiencias maternales dentro y fuera del asociacionismo $\mathrm{LGBTI}^{2}$. La búsqueda de las informantes se hizo a partir de un proceso de 'bola de nieve', partiendo de unos contactos personales iniciales. Se realizaron 44 historias de vida a 30 mujeres, de edades comprendidas entre los 30 años, la más joven, y los 60 la mayor, siendo la media de 43,1 años. Las entrevistas se realizaron en catalán y la mayoría de las informantes se expresa en este idioma durante las mismas, pero para este artículo se han traducido para facilitar su mejor comprensión. Tanto durante el contacto con las informantes, como durante las entrevistas y el análisis posterior se tuvieron en cuenta criterios éticos y de confidencialidad en el tratamiento de la información ${ }^{3}$.

Todas las informantes accedieron a TRA en clínicas privadas, ya que no se permitía, en Catalunya, en los centros de la Seguridad Social ${ }^{4}$. También todas ellas utilizaron una muestra de semen de un banco de esperma, por lo tanto semen de un donante anónimo. Las informantes fueron mujeres cisgénero, blancas, de clase media o media-alta y con un nivel cultural alto (la mayoría con estudios superiores finalizados). En relación al perfil socioeconómico y cultural la muestra resultó ser bastante homogénea, sin ser éste un objetivo previo. Las características socioculturales de las informantes se obtuvieron al final del estudio haciendo un análisis de su perfil. Ahí se pudo observar la

2 Acrónimo de Lesbianas, Gais, Bisexuales, Transgéneros e Intersexuales.

3 Se tuvieron en cuenta las orientaciones deontológicas de la FAAEE (Federación de Asociaciones de Antropología del Estado Español), aprobadas en Tarragona en septiembre del 2014. Se pueden ver en: https://bit.ly/2QEy1Jq.

4 En el momento del trabajo de campo, en Catalunya, las TRA para mujeres lesbianas o solteras no se podían realizar en la Seguridad Social. En 2014 se aprobó la Ley 11/2014, que garantiza los derechos de lesbianas, gais, bisexuales, transgéneros e intersexuales (LGBTI), pero no fue hasta 2016 que se puso en marcha un nuevo protocolo sanitario de reproducción humana asistida. Este protocolo permite que todas las mujeres tengan acceso a la cartera de servicios de la reproducción humana asistida (RHA) en los centros sanitarios públicos, independientemente de si tienen pareja o de si esta es masculina o femenina. 
homogeneidad del grupo $\mathrm{y}$, por lo tanto, los resultados del estudio se enmarcaron en ese perfil y para ese grupo de mujeres, así como en un momento sociohistórico concreto (por ej. algunas de ellas accedieron a su maternidad antes de la ley del matrimonio igualitario, antes que se pudiera acceder a las TRA por la sanidad pública, etc.).

Algunas de las informantes se autoidentificaron como lesbianas y otras no; ninguna de ellas se autodefinió como bisexual. En relación a la definición de la identidad sexual se partió de los modelos socioconstructivistas, que reflejan la manera como las personas se perciben a sí mismas y a sus principales características. Desde ahí se plantean las identidades como construidas, fluidas y múltiples (BRUBAKER; COOPER, 2000). La identidad de cada persona es el producto de su autocategorización y de la relación del individuo y su mundo social. Es por ello que se describe a las informantes a partir de su autoidentificación, de su identidad sentida, aunque en este artículo, y por una cuestión meramente descriptiva, se hablará en genérico de mujeres lesbianas.

En el artículo se plantean diversos temas en relación a las maternidades lésbicas a partir de técnicas de reproducción asistida. Por un lado, se muestra el momento en que una pareja de lesbianas se plantea la maternidad y cómo, a veces, entran en conflicto las identidades de madre y lesbiana. Por otro lado, una vez tomada la decisión de ser madres se muestran algunas de las dudas sobre dónde realizar el tratamiento de fertilidad y una vez ya se tiene una criatura el planteamiento de aumentar o no la familia. Un recorrido en el que la voz principal es la de las protagonistas, a quienes se agradece que hayan ofrecido su confianza y testimonio para poder realizar esta investigación.

\section{La Llamada de la Maternidad}

Para algunas mujeres lesbianas cuando deciden ser madres surge la duda/cuestionamiento entre dos de sus identidades: la identidad lésbica y su futura identidad maternal. En ese momento aparece una cierta lesbofobia interiorizada que incluso puede cuestionar si esas dos identidades pueden coexistir y de qué manera. En el contexto de una sociedad heteropatriarcal, cada vez más se visibilizan ejemplos cotidianos de lesboparentalidad pero todavía falta que estén representados en el escenario social como un elemento más.

La llamada de la maternidad la entendemos como aquella motivación, deseo, disposición o actitud positiva para tener criaturas. Es decir, delante de la pregunta de la entrevistadora en relación a cuando se plantea/n ser madres, las informantes dan diversas y múltiples respuestas. Hay mujeres que expresan que siempre han querido ser madres. Pilar ${ }^{5}$ es una de ellas:

\section{[...] yo siempre he querido ser madre, yo sabía que quería pasar por}

5 Pilar. Entrevista 16-2, ref. 2. Pilar y Lourdes son madres de tres nenas, las mellizas nacieron una vez acabada la investigación pero me enviaron un correo electrónico para decírmelo. En el momento de las entrevistas, Pilar tenía 38 años y Lourdes, 41. La gestante ha sido Pilar, ya que Lourdes no deseaba quedarse embarazada. Viven en un pueblo de la provincia de Barcelona. Me convocan en una cooperativa, que dispone de tienda de productos bio, una cafetería y un espacio para charlas. Acabamos haciendo las entrevistas sobre el escenario de una de las salas, como si de una obra de teatro se tratara, con la grabadora y las infusiones. 
¿Y Cómo y Dónde lo Hacemos? Experiencias Reproductivas de Mujeres Lesbianas

un embarazo. Siempre he querido pasar por un embarazo, para mi la adopción no era una opción en aquel momento[...]Y Lourdes nunca ha sentido la llamada de la maternidad, nunca ha sentido la necesidad de estar embarazada.

Hay otras informantes que, aunque hayan tenido relaciones anteriores, incluso relaciones heterosexuales anteriores, no se habían planteado tener criaturas. Blanca ${ }^{6}$ nos describe su experiencia: para ella fue encontrar la persona con quién se veía compartiendo un proyecto de maternidad y fue cuando se lo planteó:

Ent-¿Cuándo os planteáis tener hijos?

En mí surge inicialmente de una manera muy extraña, bueno [...] no muy extraña, perdón, muy de este enamoramiento de la propia relación, ¿no? Un momento muy temprano en nuestra relación en el que yo de repente cai en la cuenta, o me escuché a mí misma y me dije: es que yo contigo podría criar hijos. Y me asombré muchísimo.

Otras informantes manifiestan que siempre habían querido tener hijxs y que, $\mathrm{o}$ en pareja o en solitario, lxs tendrían. Maite ${ }^{7}$ nos dice:

Era como una cosa vital que necesitaba hacer, como aquellos objetivos vitales que tienes en tu vida. Es un proyecto realizado y compartido, que inicialmente no era para María. Ella no se había planteado tener hijos, yo creo que no, que antes de estar conmigo no lo creo.

Tal y como nos dice Imaz (2010, p. 11), ser madre tiene un significado más allá de un rol. Ser madre es una identidad plena de significados. Hay múltiples opciones para ser madre como por ejemplo tener una criatura en solitario, las llamadas madres solteras por elección (MSPE). Estas maternidades han sido estudiadas en profundidad por Jociles Rubio y Villaamil Pérez (2012). En este caso, el proyecto de familia y maternidad se define como un proyecto personal y autónomo y va desligado de la pareja y de la conyugalidad. Este es el caso de $\mathrm{Carla}^{8}$, una mujer con solvencia social, personal y económica suficiente como para ser madre soltera por elección por segunda vez. Nos explica cuándo decidió tener a su segundo hijo:

6 Blanca. Entrevista 13-1, ref.1. Blanca y Marina son madres de una adolescente. Blanca tiene 45 años y Marina tiene 60. Blanca fue la que se quedó embarazada y Marina explica que por generación ella podría ser la abuela de su hija. Viven en una casa de un pueblo pequeño. Me reciben en su casa y hacemos las entrevistas en la cocina, mientras se hace la comida.

7 Maite. Entrevista 1-1, ref. 8. Maite y María son madres de una niña y un niño. Están casadas $\mathrm{y}$ viven en un piso con una gran terraza en el área metropolitana de Barcelona y tienen dos perros. María tiene 39 años y Maite tiene 38. Maite es quién se embaraza las dos veces ya que María no quiere gestar. Hablo con ellas en diversos lugares: en el lugar de trabajo de una de ellas, en el comedor y la cocina de su casa.

8 Carla. Entrevista 11, ref.1. Carla es madre de un niño y una niña. Sus hijos provienen de un embarazo, a partir de TRA y de un proceso de adopción nacional. En el momento de la entrevista tiene 47 años. Es madre soltera por elección. Vive en un piso con una bonita terraza de una gran ciudad del área metropolitana de Barcelona. 
[...] finalmente me decidi por una cuestión de edad también, porque cuando nació Judit yo tenía 38, asi que no podía esperarme mucho más. Y en aquel momento podía y quería. Y como hacía mucho tiempo que quería, pues tiré hacia delante.

\section{¿Cómo y Dónde lo Hacemos?}

Todas las informantes de la investigación que han accedido a TRA lo han hecho en clínicas de fertilidad privadas y han realizado una IAD (inseminación artificial de donante) o bien una FIV (fecundación in vitro) con donante de semen anónimo. La elección de la clínica de fertilidad ha sido o bien por información a partir de guías de diversas instituciones, por alguna asociación LGBTI o bien a partir de la búsqueda en internet.

Las mujeres que han tenido criaturas hace algunos años explican que no había mucha información sobre cuáles eran las clínicas de fertilidad más afines a la maternidad lésbica. Hay que recordar que en aquel entonces no había ninguna ley que reconociera ni el matrimonio igualitario, reconocido legalmente en el año 2005, ni la adopción conjunta por parte de dos mujeres ${ }^{9}$. Ester ${ }^{10}$ nos lo explica así:

[...] en aquella época no había internet...yo recuerdo coger una guía que había hecho el ayuntamiento y mirar clínicas de reproducción asistida [...]

Me presento sola a la clínica y tuve una suerte increible porque la ginecóloga en la primera entrevista me dijo de una manera cercana: Bueno [...] pero ¿es un proyecto tuyo o estás en pareja? Y yo dije que estaba en pareja y la ginecóloga me preguntó: ¿Y es una mujer, verdad? Y pensé: ¡Ostras!, tanto se me nota. Pensé que era mi oportunidad de oro y le dije que sí. Ella me preguntó porque no había venido y le dije que pensábamos que no lo admitirían porque en esos momentos no era legal. Eso era el año 1994.

Los cambios legales en relación al matrimonio igualitario y la filiación conjunta facilitaron el acceso a la maternidad lésbica ya que el reconocimiento legal de las dos madres ofrecía seguridad delante de múltiples acontecimientos cotidianos (como por ejemplo las visitas médicas de urgencia, las tutorías escolares, la separación de la pareja y la regulación de la guarda y custodia, la muerte de una de las dos madres, etc.). Un ejemplo de esta situación nos lo

9 Ley 13/2005, de 1 de julio, por la que se modifica el Código Civil en materia de derecho a contraer matrimonio (BOE 157, de 1.7.2005) y en Catalunya: Llei 3/2005, de 8 d'abril, de modificació de la Llei 9/1998, del Codi de Família, de la Llei 10/1998,d'unions estables de parella, i de la Llei 40/1991, del Codi de Successions per causa de mort en el Dret Civil de Catalunya, en matèria d'adopció i tutela (DOGC 4366 de 19-04-2005).

10 Ester. Entrevista 12-2, ref.4. Ester y Dèlia son madres de una familia numerosa. Sus tres hijos provienen de procesos de adopción internacional de dos países diferentes. Una de ellas, en paralelo a los procesos de adopción, se sometió a tratamientos de TRA. Ester tiene 46 años en el momento de la entrevista y Dèlia, 49. Viven en un piso espacioso de una gran ciudad. Hacemos las entrevistas en la sala de estar y el comedor de su casa, una tranquila mañana. 
explica María"1: "Decidimos ser madres, ya lo decidíamos antes, pero seguramente nos hubiéramos decidido antes si la legislación hubiera sido favorable, no hubiéramos esperado hasta el 2005".

Panchón Iglesias y Heras i Trias (2009, p. 56) señala, en relación al tema de las adopciones, que durante muchos años tanto los hombres homosexuales como las mujeres lesbianas que querían adoptar en pareja y la ley no se lo permitía, tenían que fingir determinados aspectos de su vida personal delante de lxs profesionales que los atendían, además de asegurar administrativamente que tenían la voluntad de actuar como personas solas, cuando no era exactamente así. Lo que nos resalta Panchón para las adopciones también se puede aplicar a las clínicas de fertilidad cuando era una mujer sola que se presentaba en lugar de hacerlo con su pareja femenina, tal y como Ester explicaba en la anterior cita.

Otras mujeres que han accedido a su maternidad años después, ya han podido hacer una búsqueda por internet y mirar las webs de las clínicas. Incluso algunas clínicas actualmente ya tienen un apartado de reproducción asistida para mujeres solas y también para mujeres sin pareja masculina (así lo anuncian algunas en sus webs), obviando el término lesbiana cómo si de un tabú todavía se tratase. Algunas informantes han accedido a una de estas clínicas, tal y como Pilar ${ }^{12}$ nos explica:

Elegimos la clínica porque sabíamos que eran pioneros y que eran muy abiertos en temas de homosexualidad en parejas de mujeres [...] Lo pone en la web y todo [...] Y vamos alli y es una tranquilidad y una aceptación superfantástica y superagradable y nos sentimos supercómodas con todo el proceso [...]

La visibilidad de algunas madres lesbianas, que pertenecían a una asociación de familias de lesbianas y gais ${ }^{13}$ hace que otras mujeres lesbianas accedan a la información sobre la maternidad lésbica. Miranda ${ }^{14}$ nos lo explica así: "Leímos un reportaje de la Marisol y la María (que eran socias de la asociación de familias), que fue como nos dio más información.” Miranda nos explica como a ella le llegó la información sobre la asociación de familias y cómo la visibilidad de algunas madres lesbianas en los medios de comunicación es una herramienta de difusión e información sobre la maternidad lésbica, poco presente habitualmente en estos medios.

11 María, 39 años. Entrevista 1-2, ref. 3.

12 Pilar, 38 años. Entrevista 16-2, ref. 1.

13 Flg: www.familieslg.org.

14 Miranda. Entrevista 5-2, ref. 5. Miranda y Susan son madres de dos nenas. Miranda tiene, en el momento de la entrevista, 40 años y Susan, 41. Son originarias de América Latina y parte de su proceso migratorio viene motivado por vivir en libertad su preferencia sexual. Sus hijas han nacido a partir de un embarazo de cada una de ellas. Viven en un piso de un pueblo de la provincia de Barcelona. Nos vemos en su casa y hablamos en el comedor, con las niñas jugando por allá. 


\section{¿Cómo Decidimos ser Madres?}

La maternidad como una opción, ya sea individualmente en el caso de las madres solteras por elección o como proyecto común de la pareja, es una de las características de las familias lesboparentales. El deseo de ser madre, de formar una familia, tal y como nos señalaba Elixabete Imaz, en la que los deseos de maternidad "tienen como novedoso que se constituyen en propuestas alternativas a la familia nuclear y tienen como rasgo fundamental la voluntad de crear familia, el deseo de hacer familia o elegir hacer familia" $(2014$, p. 9). Podríamos decir que la maternidad podría ser como un ritual de paso necesario para que las mujeres lesbianas, y en general todas las mujeres, puedan ser reconocidas como adultas, mientras que la ausencia de este cambio identitario es susceptible de ser reconocido como una sospecha de inmadurez o egoísmo, coincidiendo con la interpretación de la teoría del don de Marcel Mauss (1971) de un compromiso de retorno no realizado. Esta interpretación puede ejercer cierta presión sobre las mujeres que no quieren ser madres y también sobre aquellas que lo son 'más tarde de lo socialmente establecido'.

Carme, una informante que tiene más de 50 años, después de la muerte de su padre asumió el rol de cuidadora de la familia. Fue viendo como pasaban los años y ella continuaba en la casa familiar, mientras sus hermanos se iban yendo. Estuvo hasta los 35 años sin ninguna relación de pareja estable o relación de convivencia. Actualmente está casada con Mariajo y tienen una niña, que proviene de un proceso de adopción nacional. Carme y Mariajo antes de pasar por el proceso de adopción intentan diversas veces tratamientos de fertilidad que no dan un resultado positivo. Para Carme, debido a su edad, el acceso a la maternidad a partir de TRA ya no es viable, aunque ella también manifiesta su poca motivación al respecto15: "A mí como que se me había pasado el arroz... yo no me lo había planteado nunca y mira que me gustan los críos...pero no me había planteado ser madre, ni quedarme embarazada [...]".

Para las informantes, la decisión de ser madres es una decisión consciente. Lo explican como un proceso que parte de una reflexión y un consenso de pareja, cuando la hay. La elección de quién se embaraza primero mayoritariamente es por una cuestión de edad. En general, la mayor de la pareja es quién inicia el proceso de reproducción asistida. A veces, la mayor de la pareja no desea quedarse embarazada, como es el caso de María, entonces fue su pareja quién engendró a las criaturas. En otros casos, cada mujer tiene un embarazo, como es el caso de Miranda y Susan, o más de uno como en el caso de Lola y Cinta (ella tuvo dos embarazos). Se confirma así lo que Chabot y Ames $\left(2004\right.$, p. 353) ${ }^{16}$ concluyeron en su investigación, que se realizó en Estados Unidos sobre madres lesbianas: la mujer de más edad es la que se embaraza primero.

15 Carme. Entrevista 4-2, ref.2. En el momento de las entrevistas, Mariajo tiene 47 años y Carme, 56. Viven en un piso de una gran ciudad. Nos vemos en una cafetería cercana a su casa y mientras desayunamos hacemos las entrevistas: primero con una y luego con otra. La entrevista conjunta la dejamos para después de un almuerzo familiar en su segunda residencia.

16 "The decision as to who would become the biological mother involved consideration of a variety of other factors. Age was often the starting point for who would attempt pregnancy, with the oldest partner attempting pregnancy first." 
Otra pareja de informantes, Miranda y Susan tienen dos hijas producto de un embarazo cada una. Miranda ${ }^{17}$ nos explica el tiempo que estuvieron decidiendo tener filiación: "Cuando lo decidimos fue como un año para tomar la decisión de cómo lo haremos, yo creo." Por otro lado, Susan ${ }^{18}$ nos cuenta cuáles fueron los criterios para decidir quién se embarazaría: "Entonces dijimos que sean razones médicas, entonces fuimos y hablamos con el doctor, y el doctor, es básicamente lo que planteó, quién sea la mayor que lo haga primero."

Paula $^{19}$, otra informante, tiene una hija de una relación lésbica anterior. Con su actual pareja también quiere tener descendencia y han decidido que sea ella la que se embarace. Ella reafirma esta idea de la edad: "Ent-¿Quién decide embarazarse? Las dos queríamos, o sea ella también quiere, pero por la edad empiezo yo". Como ya es sabido, la medicina recomienda embarazarse antes de los treinta y cinco años, ya que a partir de esa edad a la mujer sólo le quedan aproximadamente un $10 \%$ de la reserva total de óvulos, según datos del Institut Marquès ${ }^{20}$ y los que quedan son de peor calidad. A los treinta y siete años se considera que empieza a caer la fertilidad de la mujer y, cuanto mayor es, las posibilidades de embarazarse se reducen significativamente. A los cuarenta años una mujer tiene sólo un $5 \%$ de posibilidades de quedarse embarazada de forma espontánea. Además, se considera un embarazo de riesgo. La medicina recomienda como edad óptima para que una mujer pueda embarazarse entre los veinticinco y los treinta años, pero la realidad social y laboral obliga habitualmente a posponerlo. Así, la edad es uno de los factores en las TRA que decidirá cuál será la mujer que se embarazará. Antes de llegar a este punto hay toda una reflexión alrededor de la maternidad y de lo que significa ser madre y, en el caso de ser una pareja, un consenso sobre esta cuestión. Hay un doble discurso alrededor de la maternidad lésbica: las mujeres lesbianas son madres como cualquier otra mujer y las mujeres lesbianas ejercen unas maternidades diferentes, que están relacionadas con la lesbofobia social, la heteronormatividad y sus efectos/presiones sobre estas mujeres y sus familias. En las familias lesboparentales se puede observar habitualmente una flexibilidad en los roles sociales, hay dos figuras femeninas que realizan todos los roles familiares, un nivel alto de confianza en sí mismas y de autosuficiencia. Esta visión de la maternidad lésbica se aleja de una deseada homogenización dentro de la heterosexualidad convencional y apunta hacia verdaderas vidas, unas vidas vivibles como diría Butler (2006), y necesidades de las mujeres lesbianas y sus familias.

17 Miranda, 40 años. Entrevista 5-2, ref. 3.

18 Susan, 41 años. Entrevista 5-1, ref. 5.

19 Paula. Entrevista 3-2, ref. 1. Paula y Nadia son madres de unas gemelas, que nacen después de hacer las entrevistas. Paula tiene una hija de una anterior pareja y tiene la guarda compartida en régimen de semanas alternas. Aunque su primera hija la tuvo con su expareja todavía legalmente no han resuelto esta cuestión ya que su expareja la inscribió como hija de madre soltera. Paula y Nadia están casadas. Paula tiene 36 años y Nadia tiene 31 . Viven en una planta baja de un pequeño pueblo. Hacemos las entrevistas en el comedor de su casa, una detrás de la otra.

20 Disponible en: $<$ http://institutomarques.com/ca/>. 


\section{¿Tendremos más Criaturas?}

Algunas informantes explican su deseo de tener más de una criatura, no quieren que sea hijx únicx, que les gustaría tener más para que puedan tener compañía de juegos, para aprender a compartir, etc. Parece que la idea de tener más criaturas reafirma la noción de familia. Weston en su etnografía ya nos hablaba de como las criaturas dan validez y legitimidad a la familia (2003, p. 228): “[...] lo importante era la noción -que compartían en Estados Unidos los heterosexuales y algunos gais y lesbianas- de que los niños completaban o legitimaban la familia". En palabras de algunas informantes:

-Joana ${ }^{21}$ : yo no quería tener sólo una hija, porque pienso que no aprenden a compartir

-Mar ${ }^{22}$ también expresa su deseo y el de Roser por tener más hijxs: Sí, yo quiero tener más hijos, y Roser también, no me gustaría que Rut fuera hija única.

Algunas mujeres que ya tienen una hija, como por ejemplo Virgi e Isabel tampoco descartan tener otra. De hecho ellas han guardado embriones congelados. Isabel ${ }^{23}$ nos dice:

\section{Ent- ¿Queréis tener más?}

Nuestra idea, nos gustaría, nos gustaría por muchos factores tener más, que también los pudiera tener Virgi. Pero pienso que ella está entrando en la menopausia, pero esto ya te lo explicará ella. Ya tiene 43 años.

Aunque está el tema de la edad de Virgi, también hay una cuestión económica, los gastos que comporta una FIV y la conciliación laboral y familiar son aspectos que también influyen: "Es un poco complicado, al principio era más economía, ahora quizás es más el tiempo, no sé. No hemos cerrado el tema. Hay óvulos congelados. Están ahí’.

En el caso de Lola y Cinta, su tercer hijo aparece por la motivación de Lola $^{24}$ de vivir un embarazo y un parto. Lo explica así:

21 Joana. Entrevista 14-01, ref. 6. Joana y Montse forman una familia reconstituida. Montse tiene 41 años y tiene un hijo de una relación heterosexual anterior. Joana tiene 46 años y tiene un hijo y una hija, también de una relación heterosexual anterior. Viven en un pequeño pueblo de la provincia de Barcelona. Durante mi investigación su convivencia y su relación de pareja se acaba, me lo explicó una de ellas, mientras la otra ni mencionó el tema.

22 Mar. Entrevista 2-1, ref. 26. Mar y Roser son madres de una nena. Mar tiene 33 años en el momento de la entrevista y Roser, 30. Son una pareja joven vinculada profesionalmente a la educación y con unos valores e ideales que se podrían considerar "alternativos". Viven en un pequeño piso de una gran ciudad. Hacemos las entrevistas entre la sala de estar y el comedor, antes y después de que me invitaran a almorzar.

23 Isabel. Entrevista 15-2, ref. 2 y 3. Isabel y Virgi son madres de una niña. Isabel tiene, en el momento de las entrevistas, 38 años y Virgi, 45. Isabel ha sido la madre gestante aunque es Virgi quien prueba primero a partir de inseminación artificial de donante anónimo (IAD), pero no se queda embarazada. Ellas hicieron una lactancia inducida, compartiendo unos meses de lactancia, a partir de un proceso hormonal de inducción de la lactancia. Viven en un pueblo de la provincia de Barcelona. Me citan en el lugar de trabajo de una de ellas y hacemos las entrevistas entre jarrones y flores. 
¿Y Cómo y Dónde lo Hacemos? Experiencias Reproductivas de Mujeres Lesbianas

Ent- ¿Y el tercero?

El tercero casi no lo tenemos. Porque yo lo quería tener y la Cinta no.

Ent-¿Por qué?

Porque Cinta me decía que si fuésemos una pareja heterosexual, habríamos tenido 2, y posiblemente tenía razón en lo que decía. Ent¿Por qué?

Bueno, porque es verdad, 3 a veces son multitud. Pero al ser una pareja no heterosexual, somos homosexuales, yo también tenía ganas de quedarme embarazada y de parir.

Cinta $^{25}$ explica este deseo de Lola y la posibilidad de ampliar la familia con un cuarto hijo. Casualmente, o no, las dos provienen de familias numerosas:

Lola me dice que quiere tener la experiencia de un embarazo. Lo hablamos, de pasar de dos hijos a tres, es dinero y también trabajo. Ostia!, otro bebé!! Nos lo planteamos. Priorizamos el hecho que ella como mujer tiene derecho a vivir esta experiencia.

Ent-¿Os habéis planteado tener más hijos?

No, bueno... Nos hemos planteado que tendríamos otro, aunque ahora ya no. Pero si hubiéramos podido por tiempo y dinero...si hubiéramos tenido disposición de tiempo...igual hubiéramos tenido un cuarto.

Ent-¿Quién lo hubiera tenido?

Quizás Lola. Lo habíamos dicho, pero lo hablas y sinceramente lo dices, lo sientes desde el corazón lo haríamos, pero no tenemos ni tiempo ni dinero para hacerlo.

Claramente hemos observado como Cinta respeta la decisión individual de Lola de vivir un embarazo, de hacer pasar su maternidad también por su cuerpo, aunque ella con dos hijos hubiera tenido suficiente. Incluso se plantean la posibilidad de ampliar la familia a un cuarto hijo y que también sea Lola quien se embarace, parece que como una cuestión de equidad: dos embarazos cada una. Pero finalmente esta posibilidad se descarta por una cuestión de disponibilidad tanto de dinero para acceder a las TRA como de tiempo para conciliar vida familiar y laboral.

En el caso de Mercè y Mònica, que ya tienen una niña, es Mònica quien se plantea la ampliación de la familia y es Mercè quien pone su cuerpo a disposición de la pareja para tener otra criatura. Así nos lo describe Mercè26:

24 Lola. Entrevista 6-1, ref. 4. Lola y Cinta son madres de tres niños. La madre de Cinta vivió con ellas durante un tiempo y hasta su muerte. En el momento de la entrevista, Cinta tiene 47 años y Lola, 43. Se conocen por temas laborales y están vinculadas profesionalmente al mundo sanitario. Viven en un espacioso piso de una ciudad mediana de la provincia de Barcelona. Hacemos las entrevistas en su habitación, sentadas en la cama, con intimidad.

25 Cinta, 47 años. Entrevista 6-2, ref. 9, 10 y 11.

26 Mercè. Entrevista 7-1, ref. 13. Mercè y Mònica son madres de un niño y una niña. En el momento de la entrevista, Mònica tiene 46 años y Mercè, 43. Se definen como lesbianas feministas. Viven en una gran ciudad. 
[...] nos planteamos la posibilidad de tener otro hijo, Mònica tenía ganas. Nos lo pasamos muy bien el primer año, el segundo y el tercero. Y nos lo planteamos cuando Júlia ya tenía cuatro años".

"El deseo de maternidad de Mònica a través de mi cuerpo. En la pareja hay pactos, siempre he sido como muy respetuosa, yo estaba en aquel momento de ahora o nunca. Entonces acepté la hormonación, de hecho nos dijeron que si no era así, no sería.

La edad avanzada de las mujeres hace que ya no se planteen tener más criaturas. Algunas de las informantes que ya están alrededor de los cuarenta y cinco, o por encima de los cincuenta, lo explican como un motivo más para no aumentar la familia. Tanto Carme ${ }^{27}$ como Pietat ${ }^{28}$ nos lo dicen: "No nos hemos plantado tener más hijos por la edad, si tuviera cuarenta no me importaría, pero ahora no." "(Ent-¿Queréis tener más hijos?) No, ya somos mayorcitas, yo creo que ya no."

\section{Ideas Gestadas}

En este apartado final se presentan algunas de las ideas producidas durante el artículo, algunas conclusiones o reflexiones en relación a las comaternidades lésbicas y el acceso y uso de las técnicas de reproducción asistida.Son las ideas que se han ido gestando a lo largo del artículo.

En primer lugar, hemos observado que las informantes cuando acceden a la maternidad lo hacen venciendo su lesbofobia interiorizada, reforzada por una sociedad heteropatriarcal que todavía visibiliza a las mujeres cisgénero lesbianas como estériles.

En segundo lugar, la mayoría de las informantes tuvieron que acceder a las TRA en clínicas de fertilidad privadas ya que por el contexto histórico no se podía acceder a la sanidad pública. Este hecho provocó un claro sesgo de clase social, permitiendo que accedieran a la maternidad sólo aquellas mujeres cisgénero lesbianas que disponían de un nivel económico determinado (clase social media-alta). Este hecho también provocó que finalmente la muestra de la investigación fuera homogénea (mujeres lesbianas cisgénero, blancas, etc.).

En tercer lugar, la ausencia de una legislación que protegiera la comaternidad y los derechos de filiación hizo que algunas de las informantes se plantearan su maternidad cuando existiera esa regulación. El reconocimiento legal del matrimonio igualitario y la coadopción por parte de dos personas del mismo género facilitó también la visibilidad de la maternidad lésbica. Esa visibilidad también ayudó a visibilizar clínicas de fertilidad privadas que eran más 'lesbofriendly' y un acceso más asequible a la información para las futuras madres.

\section{Carme, 56 años. Entrevista 4-2, ref. 8.}

28 Pietat. Entrevista 8-1, ref. 4. Pietat y Conxita son madres de un niño a partir de un proceso de adopción nacional, pero antes una de ellas se sometió a diversos tratamientos de TRA. Pietat tiene 46 años y Conxita tiene 42 . Viven en un pequeño piso de una gran ciudad. Me reciben en el comedor de su casa y charlamos tranquilamente con una infusión hasta la hora de la salida de la escuela de su hijo. 
En cuarto lugar, en el caso de una pareja en que las dos mujeres cisgénero lesbianas quieran gestar, la decisión es en función de la edad: será la mayor la que gestará primero. Esta decisión se toma por cuestiones biológicas, en relación a la reserva de óvulos y la calidad de los mismos, que disminuye a medida que avanza la edad de las mujeres.

En quinto lugar, la decisión de ampliar o no la familia se basa en diversos motivos. El coste económico de las TRA, la edad avanzada de la mujer que quiere gestar y las dificultades de conciliación familiar y laboral son los motivos principales para no tener más filiación, como les puede suceder también a otros modelos familiares. En cambio, para otras parejas de lesbianas la posibilidad que las dos puedan gestar, en el caso de desearlo, se plantea como un motivo para ampliar la familia.

Hay que reconocer que, en relativamente poco tiempo, se han producido grandes avances legislativos en relación a los derechos de las personas LGBTI en España, aunque como siempre, la realidad va por delante de la legislación y quedan ciertos aspectos pendientes de regular, entre ellos por ejemplo la donación privada de biomaterial (con acuerdos privados notariales por ej.), la pluriparentalidad (como en el caso de Canadá), etc.

No todas las mujeres lesbianas cisgénero quieren ser madres, igual que no todas las bi, trans y heterosexuales tampoco lo quieren ser. Aquellas mujeres lesbianas que acceden a la maternidad lo han hecho partiendo de la maternidad como deseo, como proyecto de vida, como proyecto que estructura. Estas maternidades, aunque por un lado desafían el modelo heteropatriarcal por el otro las incorpora a esa sociedad desde su devenir familia (unidad social básica de la sociedad heteropatriarcal), incorporando así unas identidades/sexualidades periféricas al contexto social al sumar la identidad maternal. Este artículo ha querido visibilizar algunas de sus experiencias maternales para incorporarlas también en el imaginario social colectivo, ampliando la visión sobre las maternidades lésbicas.

\section{Bibliografía}

BRUBAKER, R.; COOPER, F. Beyond "identity". Theory and Society, v. 29, p. 1-47. 2000.

BUTLER, Judith. Deshacer el género. Madrid: Paidós, 2006.

CHABOT, J. M.; AMES, B. D. It wasn't 'let's get pregnant and go do it': Decision Making in Lesbian Couples Planning Motherhood via Donor Insemination. Family Relations, v. 53, n. 4, p. 348-356. 2004.

DONOSO, S. La familia lésbica. In: HERDT, G. Y KOFF, B. (Comps.). Gestión familiar de la homosexualidad. Barcelona: Bellatera, 2002. p. 171214.

FONSECA, C. Homoparentalidade: O ponto alfa do parentesco? In: VII RAM, Desafíos Antropológicos, Porto Alegre. Anais... Porto Alegre: 2007. p. $1-20$. 
HEQUEMBOURG, A.; FARRELL, M. Lesbian Motherhood: Negotiating Marginal-Mainstream Identities. Gender \& Society, v. 13, p. 540-557. 1999.

IMAZ, E. Convertirse en madre. Etnografía del tiempo de gestación. Madrid: Càtedra, 2010.

IMAZ, E. Maternidades lesbianas, nuevas formas familiares y derecho a elegir. GRAFO Working Papers, v. 3, n. 3, p. 6-17. 2014.

JOCILES RUBIO, M. I.; VILLAAMIL PÉREZ, F. Madres solteras por elección: representaciones sobre la fecundación sexual como via de acceso a la maternidad. Chungara, Revista de Antropología Chilena, v. 44, n. 4, p. 717731. 2012.

LEWIN, E. Negotiating lesbian motherhood: The dialectics of resistance and accommodation. In: GLENN, E. N. CHANG, G. Y FORCEY, L. R. (Eds.). Mothering: Ideology, experience, and agency. Nueva York-Londres: Routledge, 1994. p. 333-353.

MAUSS, M. Ensayo sobre los Dones: Razón y Forma del Cambio en las Sociedades Primitivas. 1923. Publicado en Sociología y Antropología. Madrid: Editorial Tecnos. 1971.

PANCHÓN IGLESIAS, C.; HERAS i TRIAS, P. Adopcions sense receptes. Diferents maneres de viure l'adopció. Barcelona: Graó, 2009.

RICH, A. Nacemos de mujer. La maternidad como experiencia y como institución. Madrid: Cátedra, 1996.

SALETTI CUESTA, L. Propuestas teóricas feministas en relación al concepto de maternidad. Clepsydra, v. 7, p. 169-183. 2008.

TUBERT, S. Mujeres sin sombra: maternidad y tecnología. Madrid: Siglo XXI, 1991.

. Figuras de la madre. Valencia: Ediciones Cátedra, 1996.

WESTON, K. Las familias que elegimos: lesbianas, gais y parentesco. Barcelona: Edicions Bellaterra, 2003.

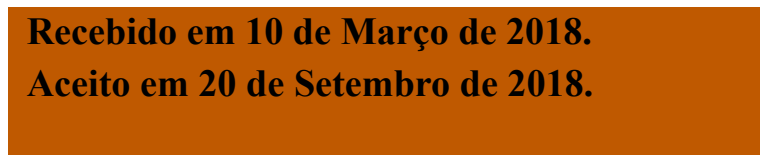

